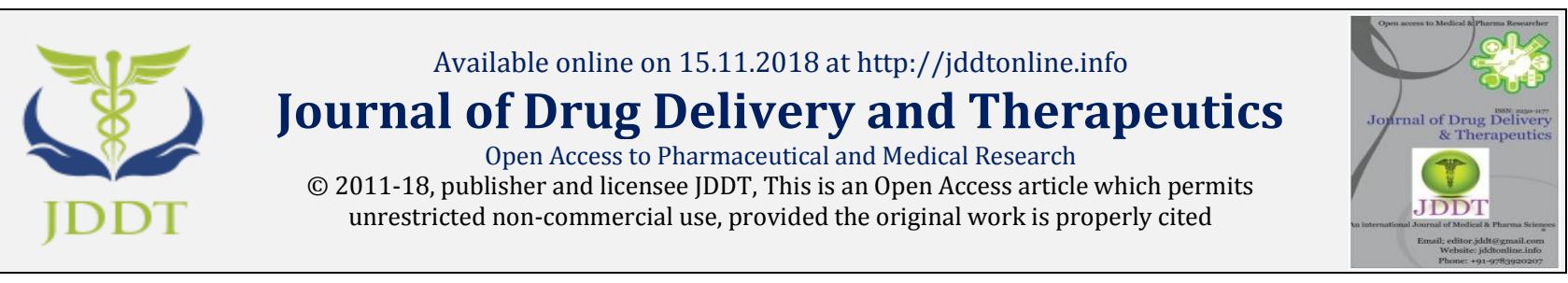

Open 2 Access

Research Article

\title{
Antimicrobial activity of Ocimum sanctum leaves extracts and oil
}

\author{
Mittal $\mathbf{R}^{\mathbf{1}^{*}}$, Kumar $\mathbf{R}^{2}$, Chahal HS ${ }^{3}$ \\ ${ }^{1}$ University college of Pharmacy, Guru Kashi University, Talwandi Sabo, Bathinda, India \\ ${ }^{2}$ Shivalik College of Pharmacy, Nangal, India \\ ${ }^{3}$ Govt Polytechnic College for girls, Patiala, India
}

\begin{abstract}
The aim of this study was to evaluate the antimicrobial effects of ethanol, Hexane and Chloroform leaf extracts of O. sanctum against pathogenic bacteria to determine their potentials as antibacterial agent. Ocimum sanctum Linn known as Holy Basil is an aromatic plant native to the tropics of Asia and Africa being medicinally important plant in the family Lamiaceae. The family Lamiaceae is one of the most exploited medicinal plant family worldwide not only as a source of medicinal plants but also with its valuable essential oils being used as spices and flavours for various food products. Leaves have petioles, and are ovate, up to $5 \mathrm{~cm}$ long, usually slightly toothed. Leaves were separated from the stem, washed in clear water and dried until they were adequately dry to be ground (dried for 7 days). Dried leaves were powdered separately in an electric grinder until a homogenous powder was obtained. Ethanolic, Hexane, Chloroform extract was prepared from the powder obtained using "cold extraction method. The activity of Tulsi extract against K. pneumonia \& Staphylococcus aureus was found to be higher at a concentration of $100 \%$ followed by $75 \%$ \& $50 \%$ respectively. The maximum zone of inhibition was found to be $21 \& 11 \mathrm{~mm}$ against Kleibsiella pneumonia and $18 \& 15 \mathrm{~mm}$ against Staphylococcus aureus. The antimicrobial efficacy of Ocimum sanctum leaves indicates that the plant possesses potent antimicrobial properties as well as Ocimum is widespread in India, it can be recommended as an easily available and renewal source of antimicrobial agent instead of synthetic chemicals.
\end{abstract}

Keywords: Ocimum santum, Staphylococcus aureus, Klebsialla pneumonia, Disc Diffusion

Article Info:

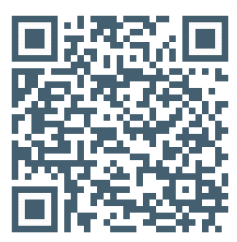

Cite this article as:

Mittal R, Kumar R, Chahal HS, Antimicrobial activity of Ocimum sanctum leaves extracts and oil, Journal of Drug Delivery and Therapeutics. 2018; 8(6):201-204ＤOI: http://dx.doi.org/10.22270/jddt.v8i6.2166

*Address for Correspondence:

Rohit Mittal, University College of Pharmacy, Guru Kashi University, Talwandi sabo, Bathinda, India

\section{INTRODUCTION}

Ocimum sanctum Linn known as Holy Basil is an aromatic plant native to the tropics of Asia and Africa being medicinally important plant in the family Lamiaceae. The family Lamiaceae is one of the most exploited medicinal plant family worldwide not only as a source of medicinal plants but also with its valuable essential oils being used as spices and flavours for various food products. Morphologically 0 . sanctum is an erect about $75 \mathrm{~cm}$ tall, much branched with hairy stems and simple opposite green leaves that are strongly scented. Leaves have petioles, and are ovate, up to $5 \mathrm{~cm}$ long, usually slightly toothed $8,9,10$

The medical world is on an immense requirement to discover novel antibiotics due to wide spread emergence of resistance among microbial pathogens against currently available antibiotics. However, traditional plants have been proved to be better source for novel antimicrobial drugs. Most of Indian plants accounts for the richest resources of natural drugs ${ }^{4}$. Historically medicinal plants have been placed at top among the source of novel drugs with antimicrobial activity. These traditional medicinal herbs have made considerable contributions to human health. In addition, plants are considered as one of the most important sources of secondary metabolites and essential oils ${ }^{5}$. On one hand the use of medicinal plants proved to be economical and effective and on the other hand they are easily available and safe to use ${ }^{6}$. Indian traditional medicinal system includes hundreds of medicinal plants related to multiple effects ${ }^{7}$. Furthermore, studies have revealed 0 . sanctum to possess anti-inflammatory, analgesic, antipyretic, antidiabetic, hepatoprotective, hypolipidemic and antistress activities 11. Extracted essential oils have also been shown to contain biologically active constituents that are insecticidal, nematicidal and fungistatic. The disc diffusion method is the commonly used technique to check the antimicrobial activity. The antimicrobial activity was tested by the method based on the principle of Kirby Bauer test. An antimicrobial is a 
substance that kills or inhibits the growth of microorganisms such as bacteria, fungi, all protozoans (Merriam-Webster Online Dictionary) ${ }^{12}$. The aim of this study was to evaluate the antimicrobial effects of ethanol, Hexane and Chloroform leaf extracts of 0 . sanctum against pathogenic bacteria to determine their potentials as antibacterial agent.

\section{MATERIAL AND METHODS}

The study employed an in vitro experimental design. Tulsi leaves were obtained from courtyards and local market from Shivalik hills of Himachal area. Authenticity of plant by Dr GS Chatha, Shivalik College, Department of Botany, Nangal. Leaves were separated from the stem, washed in clear water and dried until they were adequately dry to be ground (dried for 7 days). Dried leaves were powdered separately in an electric grinder until a homogenous powder was obtained. Ethanolic, Hexane, Chloroform extract was prepared from the powder obtained using "cold extraction method 1 . Three hundred grams of finely powdered Ocimum sanctum (Linn.) was then macerated with Tulsi (Ocimum santum) extract preparation; (a) Ocimum sanctum plant; (b) leaves separated and dried; (c) leaves ground to powder; (d) extract obtained $100 \%$ ethanol and other solvent. It was then subjected to filtration with Whatman filter paper to obtain a clear filtrate. The filtrate so obtained was reduced at a low temperature of less than $60{ }^{\circ} \mathrm{C}$ to obtain a solid residue of Ocimum sanctum (Linn.) extract $^{2}$. From 300 grams of Ocimum sanctum (Linn.) powder dissolved in 1 liter of ethanol and other solvent, 18 gram of extract (residue) was obtained and thus the yield was $6 \% \mathrm{w} / \mathrm{v}$. Accurately weigh $1 \mathrm{gm}$ of each extract was reconstituted in $10 \mathrm{ml}$ of respective solvents to obtain stoke solution in eppendorf tube. Further the dilutions were made with respective solvents. Accurately weigh of $10 \mathrm{mg}$ of Standard Gentamycin was dissolved in $10 \mathrm{ml}$ of distilled water to get $1 \mathrm{mg} / \mathrm{ml}$. The different dilutions and standard pipetted out on into the marked plates. These were left for incubation at $37^{\circ} \mathrm{C}$ for $24 \mathrm{hrs}$ and $25^{\circ} \mathrm{C}$ for 36 hrs. After incubation zones of inhibition were measured (from antibiotic zone measurement scale) in $\mathrm{mm}$ and compared with standard.
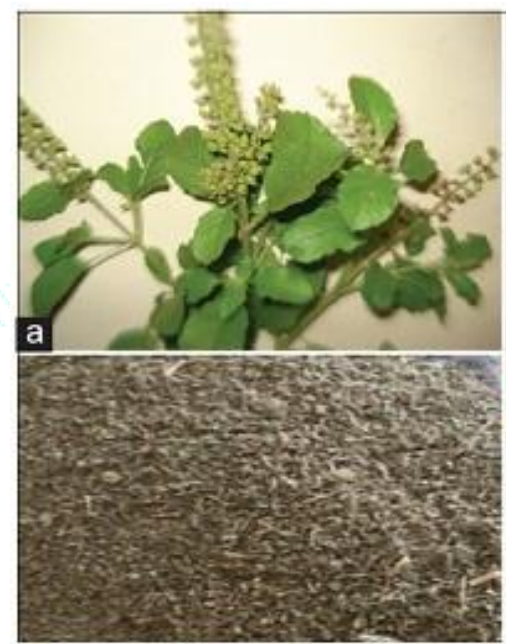

\section{Collection of test organism}

Collection of test organism and preparation of stock culture: The following strains were obtained for the antimicrobial tests. Gram negative bacteria were Klebsiella pneumoniae and Gram positive bacteria were Staphylococcus aureus. All the microbial strains were obtained from Microbial Type Culture Collection (MTCC), Chandigarh. Nutrient broth medium was prepared and autoclaved. After the bacterial cultures were inoculated to separate flasks and incubated in shaker for 24 hours

\section{Microbiological Assay}

The test organisms included for study were gram positive Staphylococcus aureus and gram negative Klebsialla pneumonia ${ }^{3}$.

\section{Preparation of Media}

For $100 \mathrm{ml}$ of media, $40 \mathrm{gm}$ of muller-hinton agar is dissolved in $100 \mathrm{ml}$ distilled water. $250 \mathrm{ml}$ media prepared and autoclaved at $121^{\circ} \mathrm{C}$ to $15-20 \mathrm{~min}$ at $15 \mathrm{lbs} / \mathrm{inch}^{2}$.

\section{Preparation of Disk}

Freshly prepared and sterilized molten media was poured onto Petri plates inside Laminar and after pouring UV light turned on to avoid contamination on plates while media

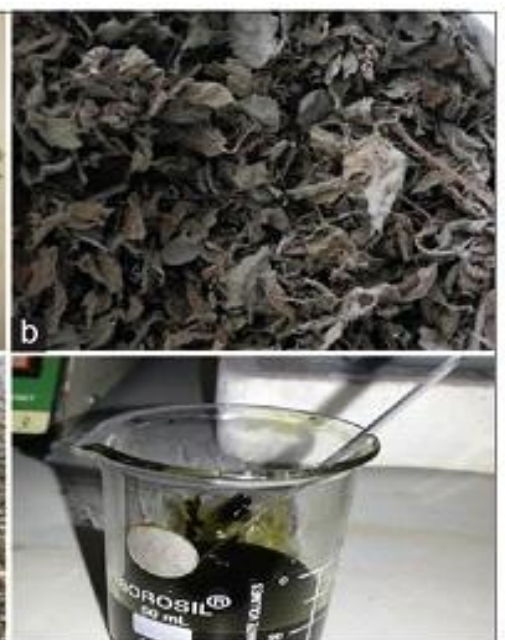

solidifying. It was left for half an hour for proper solidification.

After media gets solidified than UV light is turned off and $10 \mu \mathrm{l}$ of bacterial suspension pipetted into plates and swabbed. Sterile discs were put (with the help of forceps) on plates along with one disc of standard (6 disk was put on a plate).

\section{RESULT}

The result of antibacterial activity of Ocimum sanctum against Staphylococcus aureus, and Klebsialla pneumonia with different concentration. The least zones of inhibition were displayed by the negative control and Gentamycin exhibited the widest zones of inhibition against all the bacteria. Tulsi leaves' extract showed increasing zones of inhibition. Results of the study were shown in the table 1 . We observed that 0 . sanctum have a potent antibacterial activity. The ethanolic extract showed maximum antibacterial activity followed by hexane and pure oil extracts against $\mathrm{S}$. aureus and K. pneumonia. etc. (Table 1 and 2). The activity of Tulsi extract against K. pneumonia \& Staphylococcus aureus was found to be higher at a concentration of $100 \%$ followed by $75 \%$ \& $50 \%$ respectively. The maximum zone of inhibition was found to be $21 \& 11 \mathrm{~mm}$ against Kleibsiella pneumonia and $18 \& 15 \mathrm{~mm}$ against Staphylococcus aureus. 
Table 1: Tulsi leaves serial dilution showing the Zone of inhibition (in $\mathrm{mm}$ ) against Kleibsiella pneumonia (Gram negative bacteria)

\begin{tabular}{|l|l|l|l|l|l|l|l|}
\hline & Dilution 1 & Dilution 2 & Dilution 3 & Dilution 4 & Dilution 5 & Dilution 6 & Gentamycin \\
\hline Chloroform extract & 15 & 12 & 11 & 9 & 7 & 7 & 17 \\
\hline Haxane Extract & 6 & 4 & 4 & 3 & 3 & NZ & 17 \\
\hline Alcoholic Extract & 18 & 16 & 14 & 14 & 13 & 10 & 17 \\
\hline Pure oil & 7 & 7 & 6 & 5 & 5 & 4 & 17 \\
\hline
\end{tabular}

Table 2: Tulsi leaves serial dilution showing the Zone of inhibition (in $\mathrm{mm}$ ) against Staphyiococcus aureus(Gram positive bacteria)

\begin{tabular}{|l|l|l|l|l|l|l|l|}
\hline & Dilution 1 & Dilution 2 & Dilution 3 & Dilution 4 & Dilution 5 & Dilution 6 & Gentamycin \\
\hline Chloroform extract & 11 & 11 & 10 & 9 & 5 & 4 & 17 \\
\hline Haxen Extract & 9 & 7 & 7 & 4 & 3 & 2 & 17 \\
\hline Alcoholic Extract & 21 & 19 & 18 & 16 & 14 & 10 & 17 \\
\hline Pure oil & 8 & 7 & 7 & 3 & 2 & NZ & 17 \\
\hline
\end{tabular}

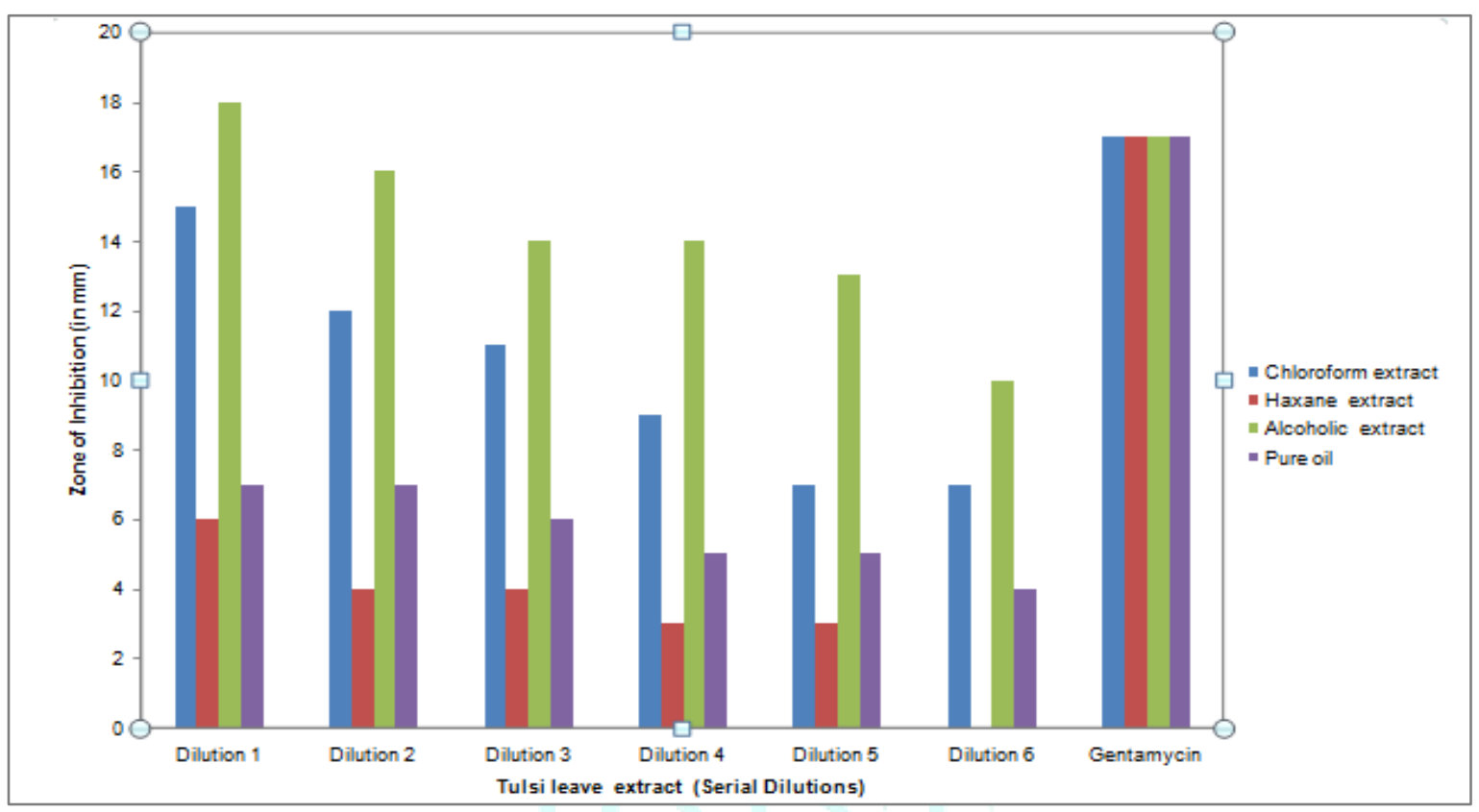

Figure 1: Tulsi leaves serial dilution showing the Zone of inhibition (in mm) against Kleibsiella pneumonia (Gram negative bacteria).

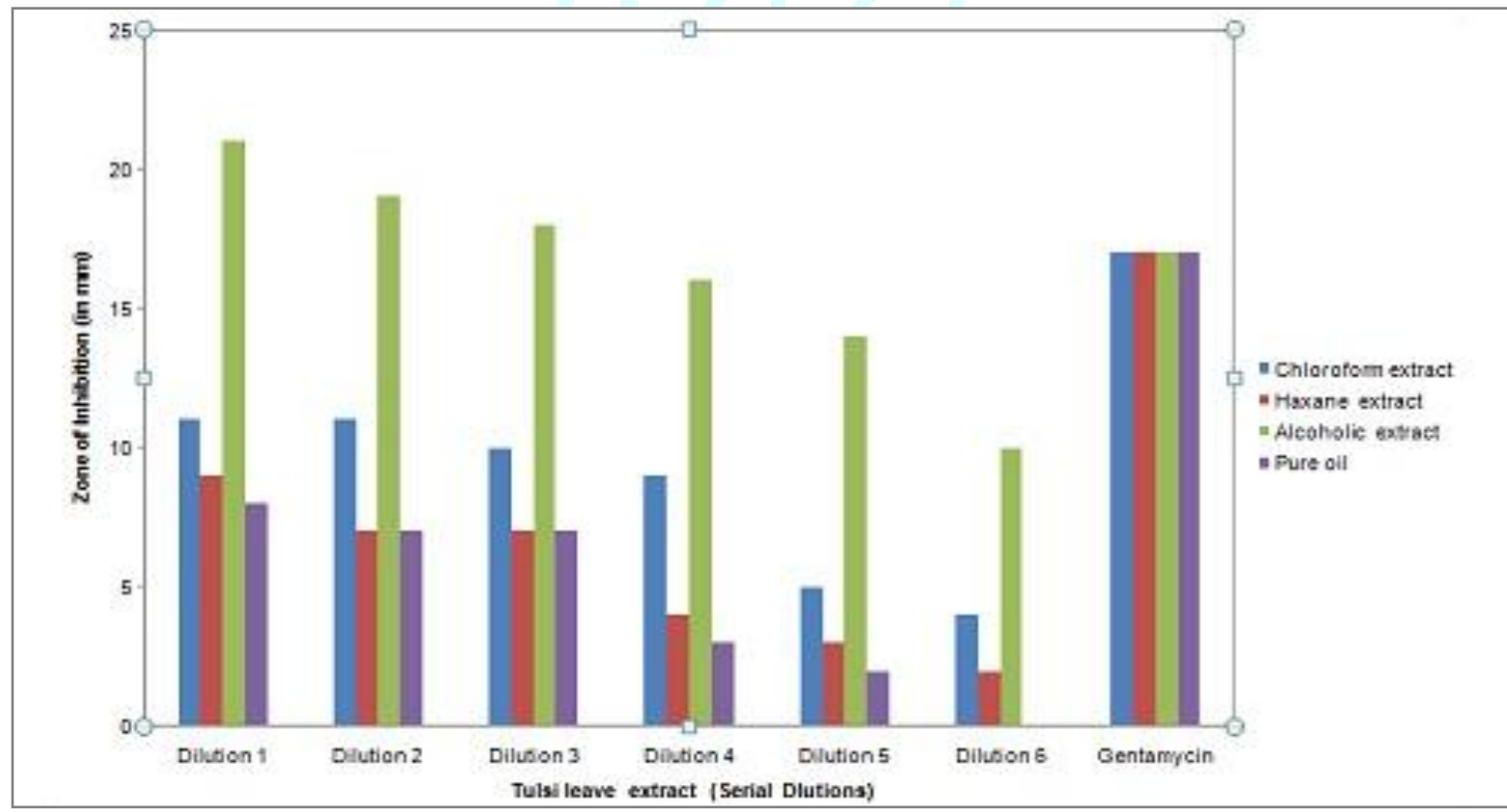

Figure 2: Tulsi leaves serial dilution showing the Zone of inhibition (in $\mathrm{mm}$ ) against Staphyiococcus aureus (Gram positive bacteria). 


\section{DISCUSSION}

Antibacterial activity of different Ocimum sanctum extracts against Kleibsiella pneumonia (Gram positive becteria) and Staphylococcus aureus (Gram negative becteria) were studied. According to the results, all different types of extracts obtained from Ocimum sanctum leaves shown to be with antibacterial activity against tested microbial pathogens. Ocimum extract has found to be with antimicrobial properties against Staphylococcus aureus and Kleibsiella pneumonia. Highest antibacterial activity was shown by ethanol and chloroform extracts against both gram-negative bacteria (Staphylococcus aureus) and grampositive bacteria (Kleibsiella pneumonia). Chloroform extract shown higher antibacterial activity against gram negative bacteria compared to gram positive bacteria and ethanolic extract shows higher activity against gram

\section{REFERENCES}

1. Mallikarjun S, Rao A,Rajesh G, Shenoy R, Pai M. Antimicrobial efficacy of Tulsi leaf (Ocimum sanctum) extract on periodontal pathogens: An in vitro study. J Indian Soc Periodontol; 2016; 20:145-50.

2. Eswar P, Devaraj CG, Agarwal P; Anti-microbial Activity of Tulsi \{Ocimum Sanctum (Linn.)\} Extract on a Periodontal Pathogen in Human Dental Plaque: An Invitro Study; Journal of Clinical and Diagnostic Research. 2016; 10(3):ZC53-ZC56.

3. Ali H, Dixit S; In vitro antimicrobial activity of flavanoids of Ocimum sanctum with synergistic effect of their combined form; Asian Pacific Journal of Tropical Disease 2012; S396S398.

4. Hammer KA, Carson CF, Riley TV, Antimicrobial activity of essential oils and other Plant extracts. J Appl Microbiol. 1999; 86:985-990.

5. Singh V, Amdekar S, Verma O, Ocimum Sanctum (tulsi): Biopharmacological activities. Web Med Cent. Pharmacolo. 2010; 1:1-7.

6. Govind $\mathrm{P}$, Madhuri S, Autochthonous herbal products in the treatment of cancer. Phytomedica. 2006; 7:99-104.

7. Rahal A, Singh V, Mehra D, Rajesh S, Ahmad AH, Prophylactic efficacy of Podophyllum hexandrum in alleviation of immobilization stress induced oxidative damage in rats. J Nat Prod 2009; 4:110-115. positive bacteria compared to gram negative bacteria in the present study. The activity of Tulsi extract against Kleibsiella pneumonia \& Staphylococcus aureus was found to be higher at a concentration of $100 \%$ followed by $75 \%$ \& $50 \%$ respectively. As the concentration of extract increases, the activity also increases and thus the zone of inhibition too increases. Significant results were shown by Kleibsiella pneumonia and Staphylococcus aureus.

\section{CONCLUSION}

The present study clearly indicates that Ocimum sanctum is a rich source of phyto-chemical constituents. The antimicrobial efficacy of Ocimum sanctum leaves indicates that the plant possesses potent antimicrobial properties as well as Ocimum is widespread in India, it can be recommended as an easily available and renewal source of antimicrobial agent instead of synthetic chemicals.

8. Jirovetz, L., Buchbauer, G., Shafi M.P. and, Kaniampady M. M. Chemotaxonomical analysis of the essential oil aroma compounds of four different Ocimum species from southern India. European Food Research and Technology, 2003; 217(2):120-124.

9. Malima, S. M., Massaga, J. J., Malecela, M. N. and Andrew, Y. Repellence effectiveness of essential oils from some Tanzanian Ocimum and Hyptis plant species against afrotropical vectors of malaria and lymphatic filariasis. Journal of Medicinal Plants Research, 2013; 7(11):653-660.

10. Kaya, I., Yiğit N and Benli, M. Antimicrobial activity of various extracts of Ocimum basilicum $\mathrm{L}$. and observation of the inhibition effect on bacterial cells by use of scanning electron microscopy. African Journal of Traditional, Complementary and Alternative Medicines, 2008; 5(4):363-369.

11. Baliga, M. S., Jimmy, R., Thilakchand, K. R., Sunitha, V., Bhat, N. R., Saldanha, E. and Palatty, P. L. Ocimum sanctum L (Holy Basil or Tulsi) and its phytochemicals in the prevention and treatment of cancer. Nutrition and cancer, 2013; 65(sup1):2635.

12. Gadiyar A, Ankola AV, Rajpurohit L; Evaluation of the Antimicrobial Activity of Ocimum Sanctum L. (Tulsi) Extract against Streptococcus Mutans and Lactobacillus Acidophilus An in-Vitro Study; Int J Health Sci Res. 2017; 7(4):224-228. 